\title{
O ENADE do curso de bacharelado em Design: conteúdos específicos
}

\section{Title of the Paper in English}

PISSETTI, Rodrigo Fernandes; Mestre;

Centro Universitário da Serra Gaúcha - FSG

rodrigo.pissetti@hotmail.br

\section{Resumo}

Trienalmente, os estudantes concluintes dos cursos superiores de bacharelado, licenciatura e tecnologia do Brasil são submetidos ao Exame Nacional de Desempenho dos Estudantes. O Conceito ENADE é um indicador de qualidade do Sistema Nacional de Avaliação da Educação Superior, e o seu resultado é fator fundamental para a atuação, reputação e interesses pedagógicos e es tratégicos das ins tituições de ensino superior. $O$ exame busca aferir as habilidades e competências do aluno para o exercício da profissão nas questões do componente específico, que representam $75 \%$ da nota da prova. Partindo da leitura de todos os exames até o momento aplicados aos cursos de bacharelado em Design, a presente pesquisa faz uma resumida e analítica descrição dessas questões, categorizando os seus conteúdos nas disciplinas curriculares em que são estudados e hierarquizando-os de acordo com a recorrência. A bibliografia fonte das informações e conceitos, citada nos enunciados das questões, também é apresentada e analisada.

Palavras Chave: Exame Nacional de Desempenho dos Estudantes (ENADE); bacharelado em Design; componente específico.

\section{Abstract}

Triennially, the graduating students from undergraduate programs in Brazil are submitted to the National Exam on Students' Performance (ENADE), which results are the fundamental factor to the acting and reputation of higher education institutions. The exam aims to assess the abilities and competences of the academics to the professional exercise with specific questions that represents 75\% of the test grade. Starting from the reading of the exams applied until the moment to the Bachelor's in Design courses, the present research makes an analytical description of those specific questions, categorizing the contents by disciplines of study and hierarchizing them according to the recurrence.

Keywords: National Exam on Students' Performance (ENADE); bachelor's degree in Design; specific component. 
No Brasil, os estudantes em fase de conclusão dos cursos superiores de bacharelado, licenciatura e tecnologia são submetidos ao Exame Nacional de Desempenho de Estudantes (ENADE) em um ciclo trienal. O objetivo é avaliar o seu rendimento em relação aos conteúdos programáticos dos cursos em que estão matriculados. A prova é componente curricular obrigatório que consta no histórico acadêmico e, assim, condição para a formatura do aluno - a situação irregular no ENADE inviabiliza a expedição do seu diploma pela instituição de ensino superior (IES) (PORTAL MEC, 2018; PORTAL INEP, 2018).

Realizado pelo Instituto Nacional de Estudos e Pesquisas Educacionais Anísio Teixeira (INEP), autarquia vinculada ao Ministério da Educação (MEC), o Conceito ENADE é um indicador de qualidade que faz parte do Sistema Nacional de Avaliação da Educação Superior (SINAES), criado pela Lei no. 10.861 de 14 de abril de 2004 e regulamentado por Portarias Normativas como a no 40, de 12 de dezembro de 2007. O SINAES é formado por três componentes avaliativos principais: das instituições, dos cursos e do desempenho dos estudantes (PORTAL MEC, 2018).

\section{Os indicadores de qualidade do SINAES}

Além do Conceito ENADE, atualmente o INEP é responsável pelo cálculo de outros três indicadores de qualidade da educação de nível superior, todos inter-relacionados: o Indicador de Diferença entre os Desempenhos Observado e Esperado (IDD), o Conceito Preliminar de Curso (CPC) e o Índice Geral de Cursos (IGC). O IDD diz respeito ao valor agregado pelo curs o no des envolvimento do aluno, comparando o des empenho do estudante na provas do ENADE e do ENEM. O CPC combina os resultados do ENADE (20\%) e do IDD (35\%) com a titulação e regime de trabalho do corpo docente da IES (30\%) e a percepção do estudante sobre a organização didático-pedagógica do curso, sua infraestrutura, instalações físicas e oportunidades de ampliação da formação acadêmica e profissional (15\%). Já o IGC é calculado com base na média ponderada das notas dos cursos de graduação (CPC) e de pós-graduação stricto sensu da instituição - setor supervisionado pela CAPES (Coordenação de Aperfeiçoamento de Pessoal de Nível Superior) (INEP/CGCQES, 2017).

A figura 1 explica visualmente a relação entre os indicadores, e a participação do Conceito ENADE na composição do IDD, CPC e IGC. Sozinho ele corresponde a 55\% do CPC, o que comprova seu significativo impacto na atuação, reputação e interesses pedagógicos e estratégicos das IES instaladas no Brasil. 
Figura 1: Composição do IDD, CPC e IGC.

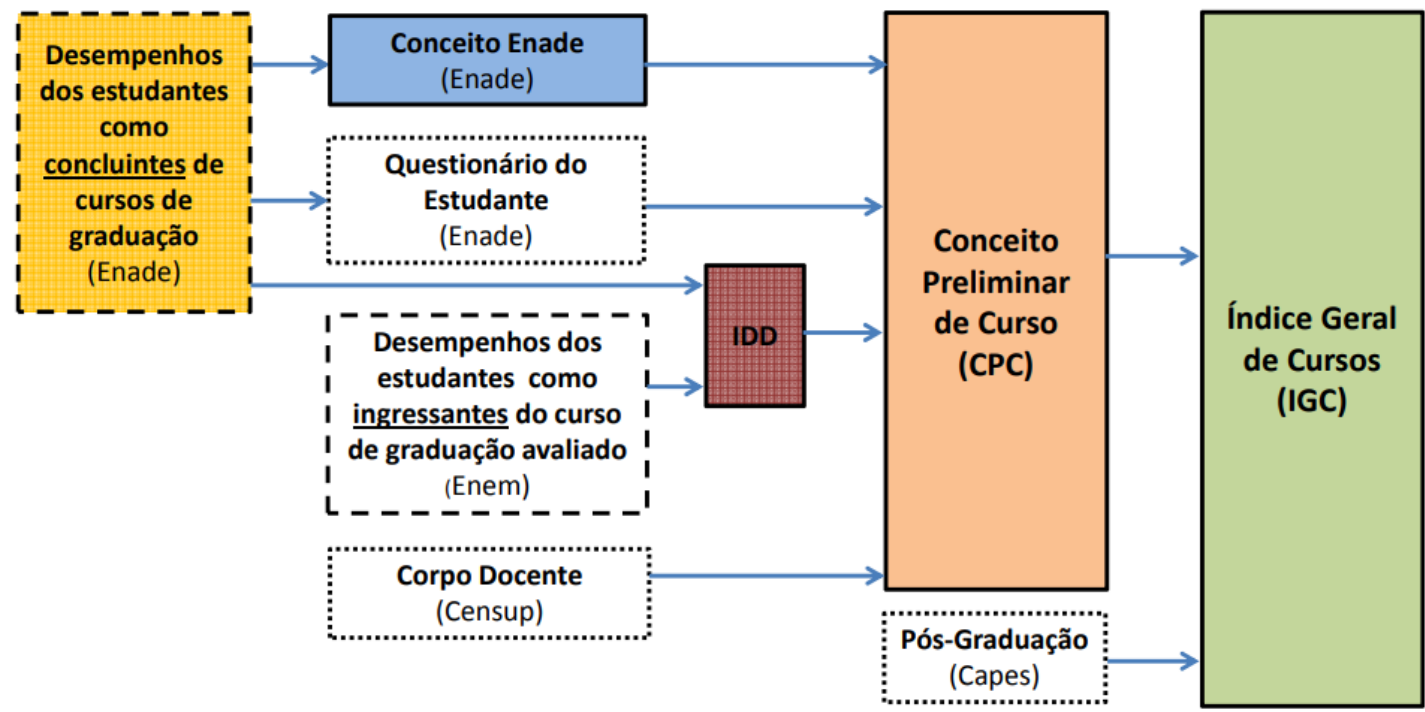

Fonte: INEP/CGCQES, 2017.

A atualização dos indicadores de qualidade da educação superior respeita a periodicidade do seu ciclo avaliativo trienal. Nos últimos três anos os cursos brasileiros foram avaliados de acordo com as seguintes áreas (cursos de bacharelado e licenciatura) e eixos (cursos superiores de tecnologia):

Áreas dos Bacharelados e Licenciaturas:

- Ano I: Saúde, Ciências Agrárias e áreas afins (2016).

- Ano II: Ciências Exatas, Licenciaturas e áreas afins (2017).

- Ano III: Ciências Sociais Aplica das, Ciências Humanas e áreas afins (2018).

Eixos Tecnológicos:

- Ano I: Ambiente e Saúde, Produção Alimentícia, Recursos Naturais, Militar e Segurança (2016).

- Ano II: Controle e Processos Industriais, Informação e Comunicação, Infraestrutura, Produção Industrial (2017).

- Ano III: Gestão e Negócios, Apoio Escolar, Hospitalidade e Lazer, Produção Cultural e Design (2018) (PORTAL INEP, 2018).

Os indicadores de qualidade são expressos em uma escala discreta crescente de valores de 1 a 5. São considerados "insatisfatórios" os cursos com notas 1 e 2 no CPC.

Em 2014, 280 cursos de desempenho insatisfatório sofreram medidas de supervisão, sendo obrigados a firmar protocolos de compromisso com o MEC para sanear seus problemas e receber visitas in loco para verificação do cumprimento das providências. Os cursos reincidentes sofreram sanções adicionais, como suspensão da autonomia do curso, exclusão do Programa Universidade 
para Todos (ProUni), redução de vagas e/ou proibição de novos ingressos (PORTAL MEC, 2014).

\begin{abstract}
Instituições de educação superior com nota inferior a 3 no Índice Geral de Cursos da Instituição (IGC) não poderão se expandir. Isso significa que não poderão construir novos campi, abrir cursos nem a umentar o número de vagas de ingresso. Além disso, os cursos já autorizados poderão sofrer redução no número de vagas ou até mesmo ter processos seletivos suspensos, após a visita de especialistas às universidades (PORTAL MEC, 2009).
\end{abstract}

Devido ao destaque do Conceito ENADE na composição dos demais indicadores - IDD, CPC e IGC -, o bom desempenho dos alunos no exame tornou-se um dos objetivos prioritários das IES. Mas atingir um resultado acima da média não parece ser uma tarefa fácil. Em 2015, mais de 900 cursos do país tiveram notas baixas no ENADE (CANCIAN, 2017). Ao comentar os números de 2016, ano em que foram avaliados 4.300 cursos de 997 instituições de ensino superior, a presidente do INEP Maria Inês Fini alerta que "o desempenho dos estudantes precisa melhorar. A maior parte dos inscritos alcançou resultado mediano nos conceitos avaliados no exame". A situação é ainda mais grave entre as instituições particulares: no ENADE 2016, enquanto $43 \%$ das universidades federais obtiveram conceito 4 e $16 \%$ o conceito 5, nas instituições particulares os percentuais foram, respectivamente, $19 \%$ e $3 \%$ (Portal MEC, 2017).

\title{
2 Metodologia e objetivo da pesquisa
}

Obviamente, assim como no caso dos demais cursos, as questões do componente específico do ENADE do bacharelado em Design são formuladas com base em uma visão geral que o INEP e MEC possuem dos campos teórico e profissional do design brasileiro, e não partem de uma exaustiva análise da matriz curricular de cada curso em funcionamento no país, levando em conta as particularidades dos seus contextos regionais. Cabe aos gestores, dirigentes pedagógicos e coordenadores de cursos das IES que almejam um bom desempenho dos seus alunos no exame se dedicarem a um monitoramento constante, conferindo se os seus projetos pedagógicos, disciplinas, planos de ensino e programas de aulas estão contemplando de fato o que é cobrado nas provas, e se os seus conteúdos programáticos estão alinhados e abordando com a mesma ênfase os assuntos do ENADE. A presente pesquisa foi realizada justamente com a intenção de fornecer alguns parâmetros e subsídios para esse processo.

Partindo da leitura de todas as provas até o momento aplicadas no ENADE dos cursos de bacharelado em Design, este estudo faz uma analítica descrição de suas questões, relacionando os conteúdos com as disciplinas curriculares em que comumente são estudados e hierarquizando-os de acordo com a recorrência. A bibliografia fonte das informações e conceitos citada nos enunciados das questões também é apresentada e comentada. O trabalho se configura em uma pesquisa bibliográfica e documental sobre dados secundários - uma vez que as pesquisas documentais podem assemelhar-se aos levantamentos elaborados com dados disponíveis não obtidos diretamente das pessoas (GIL, 2010). "A pesquisa documental é utilizada em praticamente todas as ciências sociais" (GIL, 2010, p. 30).

Segundo Gil (2010) e Marconi e Lakatos (2010), as pesquisas documentais abrangem 
materiais de finalidades diversas, tais como cartas, registros, assentamentos, autorizações, comunicações, estatísticas etc. "O conceito de documento é bastante amplo, já que pode ser constituído por qualquer objeto capaz de comprovar algum fato ou acontecimento" (GIL, 2010, p. 31). "Livros, artigos de periódicos e anais de eventos podem ser considerados como tipos especiais de documentos" (GIL, 2010, p. 65). Neste estudo, os principais documentos analisados são as provas do ENADE que, seguindo o pensamento de Marconi e Lakatos (2010), podem ser caracterizadas como documentos retrospectivos ou, de acordo com Gil (2010), ex-post-facto (a partir do passado).

Ao classificar as pesquisas em relação aos seus propósitos, Gray (2012) as categoriza em exploratórias, descritivas, explicativas e interpretativas. Os estudos descritivos buscam "desenhar um quadro" de uma situação, pessoa ou evento, e são apropriados para áreas novas ou pouco exploradas (GRAY, 2012). No caso do presente objeto de estudo, muitos autores já escreveram sobre o estado incipiente do design no Brasil, e seu lento ou retardado desenvolvimento devido à fatores como o dinamismo da área, a diversidade ideológica profissional, a ambiguidade entre a oferta das universidades e a demanda do mercado de trabalho, a falta de reconhecimento pelos empresários e a ausência de políticas de apoio, agravados pela escassez de grandes pensadores nacionais (BONSIEPE, 1997) (CARA, 2010) (CASTRO e BRAGA, 2011) (ESQUEF, 2011) e por um ensino acadêmico de cunho internacionalista, que desembarcou em nossas terras "de costas para o Brasil" (MELO, 2006). Além do Design ser um campo relativamente novo no país, o ENADE também é recente - passou a vigorar em 2004 - o que justifica o baixo número de publicações que forneçam um panorama consistente os relacionando.

Portanto, a realização e divulgação de pesquisas descritivas que retratem a atual situação e visão do MEC sobre o ensino do Design no país são de grande importância, no intuito de prover futuros estudos explicativos e interpretativos. "Para áreas de pesquisa já bem trabalhadas, onde já haja uma gama de informações descritivas, aconselha-se uma abordagem mais explicativa" (GRAY, 2012, p.35). Enquanto as pesquisas descritivas fazem perguntas do tipo "o que", as explicativas procuram responder perguntas do tipo "como" e "por que" (GRAY, 2012).

\section{A prova do ENADE}

Os instrumentos básicos do ENADE são uma prova e três questionários: um a ser respondido pelo coordenador do curso e dois pelo estudante, que neles registra sua percepção quanto ao seu processo formativo e dados do seu perfil socioeconômico. A prova é composta de 40 questões organizadas em uma parte introdutória com temas de formação geral, seguida pelos conteúdos específicos - ou componente específico - do curso em que o aluno está matriculado (PORTAL INEP, 2018).

Das 40 questões da prova do ENADE, 10 correspondem à formação geral e 30 ao componente específico. Com peso de $25 \%$ na nota da prova, as questões de formação geral são comuns a todos os cursos avaliados no mesmo ano, e cobram do estudante conhecimentos gerais sobre problemas contemporâneos, cultura, cidadania, globalização, meio ambiente, responsabilidade social etc. Já as questões do componente específico correspondem a $75 \%$ da nota, e visam "aferir as competências, habilidades e o domínio de conhecimentos necessários para o exercício da profissão" (PORTAL MEC, 2017). 


\section{Questões do componente específico do ENADE do bacharelado em Design}

Aqui são descritos resumida e analiticamente os temas tratados nas questões do componente específico de todas as provas do ENADE até o momento aplicadas aos alunos concluintes dos cursos de bacharelado em Design, categorizados nas disciplinas curriculares em que comumente são estudados. Uma organização hierárquica apresenta os conteúdos em ordem decrescente, dos mais aos menos cobrados, e a divisão em questões objetivas e questões discursivas revela os assuntos mais relevantes para os avaliadores - as questões discursivas tem peso maior no exame.

O ENADE passou a vigorar em 2004. No caso dos cursos de bacharelado em Design, até o momento as provas foram aplicadas nos anos de 2006, 2009, 2012 e 2015. Portanto, como cada exame é composto de 30 questões do componente específico, a presente pesquisa se concentra na descrição, análise e categorização de um total de 120 questões (ENADE/PROVAS E GABARITOS, 2018).

Em 2006 o componente específico do ENADE do bacharelado em Design foi constituído de 5 questões discursivas e 25 de múltipla escolha, mas em 2009 sua composição foi alterada para 3 discursivas e 27 de múltipla escolha, o que se repetiu nas provas de 2012 e 2015. Portanto, este estudo abrange 106 questões de múltipla escolha e 14 discursivas (ENADE/PROVAS E GABARITOS, 2018).

\subsection{Conteúdos das questões de múltipla escolha}

Os conteúdos das 106 questões de múltipla escolha do componente específico, que constituíram as quatro provas do ENADE até o momento aplicadas aos cursos de bacharelado em Design, podem ser agrupados em 15 subáreas ou disciplinas:

História do design: conteúdo presente em 24 questões

Gestão e empreendedorismo: em 22 questões

Tecnologias, materiais e processos de produção: em 20 questões

Projeto e método: em 17 questões

Ergonomia: em 12 questões

Ecodesign e sustentabilidade: em 11 questões

Estudo da forma: em 9 questões

Semiótica: em 8 questões

Noções básicas de design e sobre a atuação do designer: em 7 questões

Desenho: em 7 questões

Pesquisa em design: em 6 questões

Sinalização e pictogramas: em 5 questões

Produção gráfica: em 3 questões

Tipografia: em 3 questões

Legislação e propriedade: em 1 questão

É possível observar que a soma total dos números apresentados ao lado das subáreas ou 
disciplinas excede 106 - o número de questões de múltipla escolha. Isso porque muitas questões do ENADE abrangem mais de um assunto, tratam de conteúdos de diferentes disciplinas. E a categorização desta pesquisa enfoca prioritariamente os conteúdos.

Os conteúdos de história do design abordaram: as inovações e impacto sociocultural das escolas Bauhaus e Hochschule für Gestaltung (Escola de Ulm) e das associações Arts and Crafts e Deutsche Werkbund; as características estilísticas, formais, materiais e funci onais das produções dos movimentos Art Nouveau, Art Déco e Construtivismo Russo; a influência dos movimentos artísticos modernos Expressionismo e Dadaísmo no design; as origens do design no Brasil na década de 1960; o debate entre arte, artesanato e produção industrial; a cooperação entre designers e artesãos; o pós-modernismo dos movimentos Pop Art e Anti-Design, do grupo Strum e do Push Pin Studio.

Os conteúdos de gestão e empreendedorismo abordaram: o papel e competências exigidas do gestor de design; o diálogo em uma empresa do setor de design com os de pesquisa, engenharia, marketing, finanças e suprimentos; design e competitividade; design e inovação; leitura e uso estratégico de ferramentas de gestão como organogramas, gráficos e matrizes de decisão; programas de design corporativo; branding; visão e ações estratégicas (análise do ciclo de vida do produto, análise de cenários, integração de ativos na cadeia produtiva, propriedade industrial e intelectual); noções básicas de finanças e custos; adequações dos requisitos projetuais às limitações orçamentárias do projeto; design aberto (open source); plataforma crowdsourcing.

Os conteúdos de tecnologias, materiais e processos de produção abordaram: a definição de tecnologias, materiais e processos de fabricação no método projetual; inovação em técnicas, materiais e processos de produção; as propriedades físico-químicas dos materiais e suas implicações no processo produtivo, configuração dos objetos e necessidades do usuário; propriedades estéticas dos materiais; planejamento e controle da produção (PCP); sistemas de produção; relações das especificações tecnológicas com os fatores econômicos; implicações do processo de fabricação no tipo de material, volume de produção, configuração formal e preço final do produto; obsolescência dos produtos; o papel e importância dos mocapes e protótipos; prototipagem rápida e impressão 3D; ferramentas de interação digital; corte a laser; design e biotecnologia, engenharia genética; natureza recriada.

Os conteúdos de projeto e método abordaram: as etapas básicas de análise do problema, geração de alternativas, avaliação das alternativas, implementação e avaliação; a aplicação de ferramentas de criatividade, avaliação e controle nas diferentes etapas do design; os documentos apropriados para cada fase do projeto; relatórios, ilustrações técnicas, especificação de parâmetros, descrição de tempos e mensuração de dados nas etapas do projeto; considerações mercadológicas, sociais, econômicas e ambientais no método projetual; a influência das novas tecnologias na definição do método projetual; o emprego de conhecimento multidisciplinar no design; atualização e novos métodos de design; visões flexíveis e não lineares dos métodos projetuais e processos; ciclo de vida do produto; minimização do impacto ambiental; o papel, tipos e usos do briefing, e as circunstâncias que sua aplicação pode ser questionada; elaboração de estratégias; inovação no design.

Os conteúdos de ergonomia abordaram: a ergonomia no design de produtos, sistemas e serviços; fatores humanos; antropometria; percentis; condições físicas e psíquicas do usuário; usabilidade; análise e descrição de tarefas; design de interfaces; o uso de mocapes nos projetos 
ergonômicos; as modificações feitas no objeto pelo usuário; qualidades técnicas, ergonômicas e estéticas; variações contextuais; especificações ergonômicas para atender a maioria dos indivíduos; especificações ergonômicas de para atender grupos distintos de indivíduos; design para idosos; segurança; prevenção de erros.

Os conteúdos de ecodesign e sustentabilidade abordaram: o conceito de ecodesign; sustentabilidade socioambiental; ciclo de vida do produto; materiais empregados na produção em série e suas implicações ambientais; processos produtivos de baixo impacto ambiental; logística reversa; os princípios dos 5Rs; biônica; biomimética; o conceito de ecoconcepção e as questões de exequibilidade técnica, controle de custos e demanda de mercado; os efeitos de curto, médio e longo prazo dos objetos do design no meio ambiente e sociedade; o tecnicamente possível, o ecologicamente necessário e o social e culturalmente apreciável.

Os conteúdos de estudo da forma abordaram: elementos básicos da composição visual; técnicas visuais (simetria, harmonia, movimento etc.); princípios da Gestalt (figura e fundo, ordem, unificação, continuidade etc.); os princípios da Gestalt na análise e composição de logotipos; efeitos ópticos; cores complementares e análogas; contrastes cromáticos e acromáticos; a configuração formal como fator de inovação dos produtos.

Os conteúdos de semiótica abordaram: processos de significação; as dimensões materiais e simbólicas do design; relações entre forma e significado; a semiose designer-produto-usuário; linguagem do produto; semântica do produto; metáfora e analogia; metalinguagem; linguagens visuais na pós-modernidade: adequações à situações e indivíduos particulares e na solução de problemas específicos.

Os conteúdos sobre noções básicas de design e sobre a atuação do designer abordaram: o projeto de artefatos; design de marcas; a importância do conhecimento e trânsito interdisciplinar do designer; o designer como catalisador, aglutinador e motivador no trabalho de equipes multidisciplinares; projetos colaborativos; design de serviços; design e modismos; as questões materiais e imateriais do sistema produto-design; as relações e contradições entre o socialmente desejável, o ambientalmente recomendável, o tecnicamente factível, o economicamente viável e o culturalmente defensável.

Os conteúdos de desenho abordaram: desenho técnico; normalização ABNT; perspectiva; vista isométrica; planificação de sólidos; o desenho a mão livre e o desenho assistido por comutador (CAD) - seu papel, vantagens e uso estratégico no design.

Os conteúdos de pesquisa em design abordaram: as distinções e relações entre a pesquisa científica e a pesquisa em design; a metodologia da científica e o método projetual; a metodologia científica na construção e validação das pesquisas dos designers; pesquisa para a inovação em design.

Os conteúdos de sinalização e pictogramas abordaram: sistemas de pictogramas para sinalização; o sistema Isotipo; os pictogramas dos Jogos Olímpicos de Munique de 1972; a compreensão de códigos visuais e sistemas de sinalização por diferentes públicos; MESCRAI como ferramenta de validação de códigos visuais para sinalização.

Os conteúdos de produção gráfica abordaram: o sistema aditivo de cor-luz (RGB); a quadricromia ou tetracromia nos processos de impressão; os recursos de um processo produtivo gráfico - inputs e outputs. 
Os conteúdos de tipografia abordaram: estilos tipográficos; anatomia tipográfica; família tipográfica; legibilidade; leiturabilidade; análise tipográfica nos âmbitos sintático, semântico e pragmático.

A única questão de legislação e propriedade nas quatro provas do ENADE para o bacharelado em Design abordou a propriedade intelectual e industrial (franchising, royalties etc.) nas atividades estratégicas de design (ENADE/PROVAS E GABARITOS, 2018).

\subsection{Conteúdos das questões discursivas}

Os conteúdos das 14 questões discursivas do componente específico, que constituíram as quatro provas do ENADE até o momento aplicadas aos cursos de bacharelado em Design, podem ser agrupados em 7 subáreas ou disciplinas:

Projeto e método: 5 questões

Gestão e empreendedorismo: 2 questões

Tecnologias, materiais e processos de produção: 2 questões

Desenho: 2 questões

História do design: 1 questão

Ergonomia: 1 questão

Pesquisa em design: 1 questão

As questões discursivas de projeto e método abordaram: as etapas do projeto - análise do problema, geração de alternativas, avaliação das alternativas e implementação da solução - ou planejamento, anteprojeto, desenvolvimento, implementação e avaliação; a aplicação de ferramentas de criatividade, avaliação e controle nas diferentes etapas do projeto; a definição do problema como condição prévia na abordagem metodológica; a influência dos fatores mercadológicos e produtivos nas soluções de design.

As questões discursivas de gestão e empreendedorismo abordaram: os conhecimentos e competências exigidos de um gestor do design; gestão do design; programas e projetos de design corporativo.

As questões discursivas de tecnologias, materiais e processos de produção abordaram: os processos e tecnologias de produção e suas implicações na configuração formal e custos dos objetos projetados; as vantagens e aplicações da tecnologia de corte a laser em diferentes materiais, produtos e processos.

As questões discursivas de desenho abordaram a planificação de sólidos.

A questão discursiva de história do design tratou dos projetos dos designers brasileiros Alexandre Wollner, Aloísio Magalhães e Sérgio Rodrigues, e sua relevância para o design nacional.

A questão discursiva de ergonomia abordou os fatores humanos no design de produtos, as características técnicas, ergonômicas e estéticas relacionadas entre si e com o usuário.

A questão discursiva de pesquisa em design abordou a pesquisa experimental para investigação de estereótipos populares - situações, método e critérios para seleção dos sujeitos da amostra (ENADE/PROVAS E GABARITOS, 2018). 


\subsection{Participação dos conteúdos no componente específico}

Considerando todas as 106 questões de múltipla escolha e 14 discursivas que constituíram o componente específico das provas do ENADE até agora realizadas pelos concluintes dos cursos de bacharelado em Design, em termos proporcionais, os conteúdos cobrados foram:

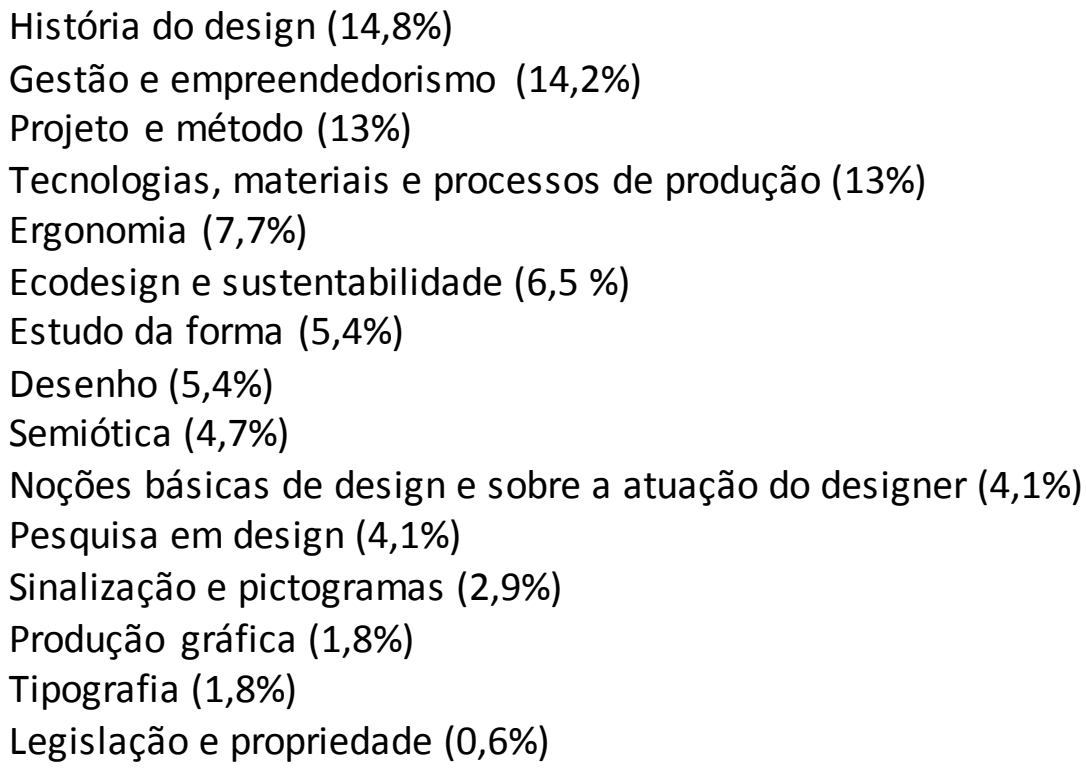

\subsection{Bibliografia citada nas questões}

As fontes bibliográficas das informações e conceitos usados na formulação de várias questões foram apresentadas junto aos seus enunciados. São títulos bastante comuns nas bibliotecas dos cursos superiores em Design do Brasil.

Foram mencionados os livros de design de produto e desenho industrial: Projeto de Produto (Mike Baxter), Design industrial: bases para a configuração dos produtos industriais (Bernd Löbach), Administração da produção (Nigel Slack, Robert Johnston e Stuart Chambers), Seleção de materiais no projeto mecânico (Michael Ashby), Ergonomia: projeto e produção (Itiro lida) e Ergonomia na prática (Jan Dul, Bernard Weerdmeester).

Os livros específicos da área do design gráfico: Textos clássicos do design gráfico (org. Michael Bierut, Jessica Helfand, Steven Heller e Rick Poynor), Design gráfico: Teoria do design gráfico (Helen Armstrong) e A prática do design gráfico: uma metodologia criativa (Rodolfo Fuentes).

Os livros sobre história do design e contextualização da área: Design: uma introdução (Beat Schneider), História, teoria e prática de design de produtos (Bernhard Burdek), O design do século (Michael Tambini), $A B C$ da Bauhaus: a Bauhaus e a teoria do design (org. Ellen Lupton e J. Abbott Miller), Objetos do desejo: design e sociedade desde 1750 (Adrian Forty), Design, cultura e sociedade (Gui Bonsiepe) e Design: do material ao digital (Gui Bonsiepe).

Livros sobre método e projeto: Design método (Luiz Antonio L. Coelho), Metaprojeto: o design do design (Dijon de Moraes), Briefing: a gestão do projeto de design (Peter L. Phillips) e Gestão de projetos: soluções práticas para os desafios do trabalho (Mary Duffy). 
Livros sobre desenho e estudo da forma: Gramática Visual (Christian Leborg) e Desenho para designers: habilidades de desenho, esboços de conceito, design auxiliado por computador (Alan Pipes).

Livros sobre ecodesign e sustentabilidade: O desenvolvimento de produtos sustentáveis (Ezio Manzini e Carlo Vezzoli), Haverá a idade das coisas leves: design e desenvolvimento sustentável (org. Thierry Kazazian), Biomimética: inovação inspirada pela natureza (Janine M. Benyus) e Biônica (Kurt G. Blüchel).

Livros sobre temas contemporâneos e tendências: As 10 faces da inovação (Tom Kelley Jonathan Littman), Design para um mundo complexo (Rafael Cardoso), Plano B: o design e as alternativas viáveis em um mundo complexo (John Thackara), Design + artesanato: o caminho brasileiro (Adélia Borges), A matéria da invenção (Ezio Manzini) e Envelhecimento bem-sucedido (Newton Luiz Terra e Beatriz Dornelles).

Os únicos livros publicados em língua estrangeira mencionados foram: Design: the problem comes first (Jens Bernser), The semantic turn: a new fundation for design (Klaus Krippendorf) e Analysis for marketing planning (Donald R. Lehmann e Russell S. Winer) (ENADE/PROVAS E GABARITOS, 2018).

\section{Considerações finais}

Na concisa descrição aqui apresentada sobre o teor das questões do componente específico das provas do ENADE para o curso de bacharelado em Design, ficou evidente a significativa ênfase sobre determinados assuntos diante de outros. A recorrência dos conteúdos de história do design $(14,8 \%)$, gestão e empreendedorismo $(14,2 \%)$, projeto e método $(13 \%)$ e tecnologias, materiais e processos de produção (13\%) refletem a importância que o INEP e MEC vem dando a esses temas, que juntos constituíram $55 \%$ das questões específicas formuladas até o momento.

É pertinente observar que nos últimos três exames a parte do componente específico foi composta de 27 de questões de múltipla escolha, com peso de $85 \%$ na nota, e 3 discursivas, com peso de $15 \%$. Ou seja, cada questão de múltipla escolha contabilizou 3,15\% da nota do componente específico, enquanto cada questão discursiva contabilizou 5\%, o que demonstra a valorização das competências do estudante na redação de textos, ortografia, gramática, raciocínio lógico, memorização etc.

As fontes bibliográficas citadas nos enunciados das questões revelam a forte presença contemporânea de teóricos e conceitos que por décadas tem sido estudados nos cursos superiores de Design - como, por exemplo, Mike Baxter, Bernd Löbach e o método projetual linear constituído pelas etapas de análise do problema, geração de alternativas, avaliação das alternativas e implementação da solução. Estas obras, juntamente com o predomínio de marcos e fatos históricos do design mundial, especialmente europeu e norte-americano (Bauhaus, Art Nouveau, Escola de Ulm etc.), comprovam a persistência do ensino acadêmico de cunho "internacionalista" apontado por autores como Chico Homem de Melo (2006).

Questões voltadas especificamente para o ensino e pensamento do design no Brasil, ou mencionando personalidades e objetos que marcaram o design nacional, constituíram uma pequena parte das provas. Talvez merecessem mais espaço nesse exame direcionado aos bacharéis 
da área, uma vez que assuntos como a problemática da identidade do produto brasileiro, por exemplo, vem sendo apontados desde a década de 1960 (CARA, 2010).

Outro aspecto para reflexão são as particularidades de cada região do país que, pela necessidade de padronização da prova aplicada em âmbito nacional, acabam sendo diluídas em uma visão genérica do que se considera o design brasileiro. Os atores e fatores identitários locais culturais, sociais e econômicos que definem o design regional podiam ter maior presença nas provas, principalmente pelo Brasil se tratar de uma nação de dimensões continentais, extremamente plural e multicultural.

Nas provas do ENADE também foram abordados temas atuais e reflexões sobre as fronteiras, interdisciplinaridade e tendências do design. Nesse ponto o referencial bibliográfico priorizou publicações nacionais, e só mencionou livros estrangeiros em três ocasiões. Cabe refletir se os autores e pesquisas brasileiras estão realmente na vanguarda em relação a esses temas.

Finalmente, é de suma importância destacar que o panorama descrito neste estudo se refere aos exames passados, e não tem a intenção de prever os assuntos componentes das edições futuras do ENADE dos cursos de bacharelado em Design.

\section{Referências}

BAXTER, Mike. Projeto de produto: guia prático para o design de novos produtos. Trad. Itiro lida. 3a edição. São Paulo: Blucher, 2011.

BONSIEPE, Gui. Design, cultura e sociedade. São Paulo: Edgard Blucher, 2011.

BONSIEPE, Gui. Design: do material ao digital. Trad. Claudio Dutra. Florianópolis: FIESC/IEL, 1997.

BÜRDEK, Bernhard E. História, teoria e prática do design de produtos. Trad. Freddy Van Camp. São Paulo: editora Edgard Blücher, 2006.

CANCIAN, Natália. Com nota baixa no Enade, mais de $\mathbf{9 0 0}$ cursos superiores terão supervisão. Folha de S. Paulo. Seção Educação. Publicado em 8 de março de 2017. Disponível em http://www1.folha.uol.com.br/educacao/2017/03/1864669-com-nota-baixa-no-enade-mais-de900-cursos-superiores-terao-supervisao.shtml Acessado em 11 de março de 2018.

CARA, Milene. Do desenho industrial ao design no Brasil: uma bibliografia crítica para a disciplina Coleção Pensando o Design. S. Paulo: Blucher, 2010.

CASTRO, Maria Luiza Almeida Cunha de; BRAGA, Juliana Cardoso. Políticas públicas de design: a construção da relevância do tema no Brasil. Revista Espaço Acadêmico, Janeiro de 2012.

ESQUEF, Marcos. Desenho Industrial e Desenvolvimentismo: As relações sociais de produção do design no Brasil. Rio de Janeiro: Synergia, 2011.

GIL, Antonio Carlos. Como elaborar projetos de pesquisa. 5a edição. São Paulo: Atlas, 2010.

GRAY, David E. Pesquisa no mundo real. Trad. Roberto Cataldo Costa. Rev. técn. Dirceu da Silva. 2a edição. Porto Alegre: Penso, 2012.

INEP/CGCQES - COORDENAÇÃO GERAL DE CONTROLE DE QUALIDADE DA EDUCAÇÃO SUPERIOR. Os Indicadores de Qualidade da Educação Superior. Seminário ENADE 2017. Brasília, Distrito Federal, 
1 de junho de 2017. Disponível em http://portal.inep.gov.br/seminario-enade Acessado em 11 de março de 2018.

ENADE - PROVAS E GABARITOS. Portal INEP. Seção Ensino Superior/Enade. Disponível em http://portal.inep.gov.br/provas-e-gabaritos3 Acessado em 11 de março de 2018.

FOLHA DE S. PAULO. Ministério examina cursos e faculdades. Seção Cotidiano, p.8. Publicado em 7 de dezembro de 2013.2 Disponível em https ://acervo.folha.com.br/leitor. do?numero=19701\&anchor=5907684\&origem=busca\&pd=881d ccaec2a7796bb851eb15cbdae5d1 Acessado em 13 de março de 2018. Acessado em 9 de março de 2018.

IIDA, Itiro. Ergonomia: projeto e produção. 2a edição. São Paulo: Blucher, 2005.

LÖBACH, Bernd. Design industrial - bases para a configuração dos produtos industriais. Trad. Freddy Van Camp. São Paulo: editora Blucher, 2001.

MARCONI, Marina de Andrade; LAKATOS, Eva Maria. Técnicas de Pesquisa: planejamento e execução de pesquisas, amostragens e técnicas de pesquisa, elaboração, análise e interpretação de dados. 7ạ edição. São Paulo: Atlas, 2010.

MELO, Chico Homem de. 0 design gráfico brasileiro: anos 60. Chico Homem de Melo (org.). São Paulo: Cosac Naify, 2006.

PORTAL INEP. Enade: perguntas frequentes. Disponível em http://portal.inep.gov.br/perguntasfrequentes 4 Acessado em 6 de março de 2018. Acessado em 9 de março de 2018.

PORTAL MEC. Ministro anuncia indicadores de qualidade e medidas para cursos insatisfatórios. Publicado em 19 de dezembro de 2014. Acessado em http://portal.mec.gov.br/ultimasnoticias/212-educacao-superior-1690610854/20990-ministro-anuncia-indicadores-de-qualidadee-medidas-para-cursos-insatisfatorios Acessado em 13 de março de 2018.

PORTAL MEC. Instituições com nota baixa não poderão abrir cursos e vagas. Publicado em 01 de setembro de 2009. Disponível em http://portal.mec.gov.br/ultimas-noticias/212-educacaosuperior-1690610854/14237-instituicoes-com-nota-baixa-nao-poderao-abrir-cursos-e-vagas Acessado em 11 de março de 2018.

PORTAL MEC. Resultado do ENADE é antecipado e revela que instituições federais superaram as particulares. Publicado em 1 de setembro de 2017. Disponível em http://portal.mec.gov.br/component/content/article?id=54031 Acessado em 11 de março de 2018.

PORTARIA NORMATIVA № 40. Institui O E-MEC, sistema eletrônico de fluxo de trabalho e gerenciamento de informações relativas aos processos de regulação, avaliação e supervisão da educação superior no sistema federal de educação, e o Cadastro e-MEC de Instituições e Cursos Superiores e consolida disposições sobre indicadores de qualidade, banco de avaliadores (Basis) e o Exame Nacional de Desempenho de Estudantes (ENADE) e outras disposições. Publicada em 12 de dezembro de 2007.2 Disponível em http://download.inep.gov.br/download/condicoes_ensino/2007/Portaria_n40.pdf Acessado em 11 de março de 2018.

TAMBINI, Michael. O Design do Século. Trad. Cláudia Sant'Anna Martins. São Paulo: editora Ática, 2004. 2a edição. 